\title{
RESENHA
}

SILVA, Glaydson José da. História Antiga e usos do passado: um estudo de apropriações da Antiguidade sob o regime de Vichy (1940-1944). São Paulo: Annablume; Fapesp, 2007, 222p.

\section{Os usos e abusos do passado na França durante o repime de Vichy}

Diogo da Silva Roiz

[...] todos os fatos e personagens de grande importância na bistória do mundo ocorrem, por assim dizerer, duas vêzes [...] a primeira como tragédia, a segunda como farsa (MARX, 1969, p. 17).

Nestes termos, Karl Marx (1818-1883), na década de 1850, resumiria sua análise de uma das obras de Hegel. Ao expor o que definiu como a 'farsa' (do Dęoito Brumário) de Napoleão III, Marx constataria que:

Doutorando em História pela UFPR, bolsista CNPq. Mestre em História pela Unesp, Campus de Franca. Professor do Departamento de História da Universidade Estadual de Mato Grosso do Sul, na unidade de Amambaí. 
Os homens fazem sua própria história, mas não a fazem como querem; não a fazem sob circunstâncias de sua escolha e sim sob aquelas com que se defrontam diretamente, legadas e transmitidas pelo passado. A tradição de todas as gerações mortas oprime como um pesadelo o cérebro dos vivos. E justamente quando parecem empenhados em revolucionar-se a si e às coisas, em criar algo que jamais existiu, precisamente nesses períodos de crise revolucionária, os homens conjuram os espíritos do passado, tomando-lhes emprestado os nomes, os gritos de guerra e as roupagens, a fim de [se] apresentar[em] e nessa linguagem emprestada (1969, p. 17-8).

Sob circunstâncias diferentes, mas com idéias semelhantes, Jean Chesneaux (1995) destacaria, na década de 1970, em sua análise da história e dos historiadores, tomando de empréstimo o debate do Le Monde de 26 de julho de 1974, que: "Tem-se sempre necessidade de ancestrais quando o presente vai mal" (1995, p. 23). Ainda na década de 1970, Georges Duby (1993), com seu livro O domingo de Bouvines, 27 de julho de 1214 (de 1973), demonstraria como aquela batalha seria recriada e adequada às circunstâncias de cada momento histórico, ao ponto de indicar os 'choques franco-prussianos'. 'Em outras palavras, o autor trabalha como um fato concreto, o enfrentamento entre Filipe Augusto da França e o Imperador Oto IV, a 27 de julho de 1214, foi adaptado a novas situações políticas" (2007, p. 15), dirá Leandro Karnal, ao apresentar a obra de Glaydson José da Silva, História Antiga e usos do passado.

Nos anos 80, Raoul Girardet, ao estudar os mitos e as mitologias políticas, lembrará que: “(...) a cada momento de sensibilidade (...) corresponde (...) uma leitura da História, com seus esquecimentos, suas rejeições e suas lacunas, mas também com suas fidelidades e suas devoções" (1987, p. 98). Neste mesmo período, Eric Hobsbawm (1997), ao enfatizar a maneira pela qual são 'inventadas certas tradições', ressaltará que: 
(...) por 'tradição inventada' entende-se um conjunto de práticas, normalmente reguladas por regras tácitas ou abertamente aceitas; tais práticas, de natureza ritual ou simbólica, visam a inculcar certos valores e normas de comportamento através da repetição, o que implica, automaticamente, uma continuidade em relação ao passado. Aliás, sempre que possível, tenta-se estabelecer continuidade com um passado histórico apropriado (...). Contudo, na medida em que há referência a um passado histórico, as tradições 'inventadas' caracterizam-se por estabelecer com ele uma continuidade bastante artificial. Em poucas palavras, elas são reações a situações novas que ou assumem a forma de referência a situações anteriores, ou estabelecem seu próprio passado através da repetição quase que obrigatória. (1997, p. 9-10)

Discordando de tais argumentos, Stephen Bann (1994) propôs pensar as representações que foram (e são) criadas sobre o passado (europeu do século XIX), com vistas a enfatizar o papel exercido pelos historiadores e pelos lugares de produção da 'memória social' como os museus, os arquivos e as universidades, ao serem elaboradas certas leituras sobre o passado.

Usar o 'passado' para dar 'sentido' às ações no 'presente', desse modo, não é algo novo nem na História (dos homens e das mulheres do passado), nem na historiografia (HARTOG, 2003). Mas a maneira com que o passado é usado para demarcar as ações e as reflexões no presente, de cada momento histórico, senão é 'nova' em todos os instantes, ao menos é múltipla. Foi esta direção que os trabalhos de François Hartog acabaram seguindo desde os anos de 1980, quando demonstrou em seu livro O espelho de Heródoto (1999) as diferentes formas de apropriação deste autor ao longo do tempo. Nesse sentido, com seu conceito de 'regimes de historicidade', Hartog se preocupou em teorizar de que modo os grupos e as sociedades do passado se apropriavam da história para fazerem diferentes usos do tempo e da relação passado-presente-futuro. 
Foi tendo em vista essas questões que Glaydson José da Silva, em seu livro História Antiga e usos do passado (que é uma versão revista de sua tese de doutorado, intitulada Antiguidade, Arqueologia e a França de Vichy: usos do passado, defendida em 14 de março de 2005, no programa de pós-graduação em História da Unicamp, sob a orientação do Prof. Dr. Pedro Paulo Abreu Funari), preocupou-se em apresentar uma análise pormenorizada das formas com que a Antiguidade e o passado gaulês, romano e galo-romano haviam sido apropriadas na França durante o Regime de Vichy, que durou entre 1940 e 1944.

Para demonstrar essa questão, o autor estudou e evidenciou a relação de diferentes temporalidades (a da Antiguidade, a do regime de Vichy na década de 1940, e a ação da direita francesa nos anos 80 e 90), para circunstanciar de que modo os passados gauleses, romanos e galo-romano estavam sendo apropriados e usados politicamente, em diferentes momentos, para justificar a ação de grupos e partidos políticos na França durante o século $\mathrm{XX}$. Com isso, o autor revela, de modo didático e inovador, as relações, nem sempre lineares, entre passado e presente, e a maneira pela qual o passado é apropriado para justificar as ações de grupos e indivíduos no presente histórico. Mais detidamente, tenta descortinar a importância da Antiguidade Clássica, para se elaborar um conhecimento mais balizado sobre a História Contemporânea. Em suas palavras:

O saber histórico é tomado mais como um espaço de desconstruções que de construções e reconstruções. Busca-se neste trabalho uma compreensão dos meandros, dos escaninhos de um domínio em que a memória e a sua destruição são recorrentes na reconstrução dos acontecimentos históricos, em que memória e esquecimento se ligam e tomam forma atendendo a imperativos circunscritos do tempo presente. (p. 17-8)

Com isso, a obra foi dividida em quatro capítulos. Em cada um deles o autor escreveu um pequeno prólogo para apresentar 
ao leitor o que discutiria no capítulo. Cada capítulo foi dividido em duas partes.

No primeiro capítulo, O caráter moderno da Antiguidade: considerações teóricas e análises documentais acerca da instrumentalização do passado, há uma descrição de como a Antiguidade foi pesquisada nos anos 80 e 90, e a maneira com que o passado é usado em diferentes momentos. Detém-se na forma pela qual o Fascismo e o Nazismo se apropriaram da Antiguidade para justificarem seus projetos nacionais e suas propostas políticas para a Europa nos anos 30 e 40 do século passado.

Essas diferentes antiguidades, ou melhor, essas diferentes leituras da Antiguidade, apontam sempre para o presentismo do pensamento antigo na elaboração das práticas políticas, das doutrinas, dos jogos identitários, enfim, das visões de homem e de mundo no Ocidente. (p. 30)

Nesse sentido, evidencia como o regime Vichy, nesse mesmo período, se apoiou no passado gaulês, romano e galoromano, e, em especial, na figura de Vercingetórix, para empreender suas ações políticas. Vale notar que a França não foi o único país Europeu que sucumbiu às ações do Nazismo e do Fascismo durante a Segunda Guerra Mundial (1939-1945), e se apoiou no passado para justificar suas ações no presente. Mesmo fora da Europa, esses regimes tiveram forte influência sobre a maneira com que o passado era usado e estudado, e a propaganda política era uma das estratégias para impor o consenso. No Brasil, Getúlio Vargas é um exemplo emblemático de como o Fascismo e o Nazismo serviram de base para que este desenvolvesse estratégias semelhantes de usar o passado e a propaganda política como formas de construir o consenso (GOMES, 1996).

No segundo capítulo, A Antiguidade a serviço da colaboração: nas trilhas da memória, a reescrita da História na França dominada (19401944), o autor demonstra como a História e a Arqueologia romana e galo-romana francesas se moveram e foram usadas durante o período de ocupação alemã no país. Ao discutir a historiografia sobre o Regime de Vichy, o autor mostra como o período é pouco 
conhecido, mesmo em parte significativa do povo francês. Além disso, ao se ocupar da questão nacional, enfatiza como após a Revolução Francesa os usos do passado romano, gaulês e galoromano foram cada vez mais frequentes na história francesa contemporânea. A partir da análise de manuais de História, artigos de jornal e discursos, o autor reconstitui os diferentes usos que foram feitos, durantes esse período, da figura de Vercingetórix e dos gauleses "pela Révolution National - termo designado pelo Marechal Philipe Pétain para referir-se à retomada à ordem no país após a derrota militar" (p. 20). Destaca ainda como a História e a Arqueologia serviram de base na construção de um consenso, ao serem utilizadas como instrumentos de afirmação e legitimação, quando o regime procurou declaradamente romper com as tradições republicanas do passado francês.

No terceiro capítulo, Jérôme Carcopino - um bistoriador da Antiguidade sob Vichy, indica a importância deste intelectual com sua obra, e seus estudos sobre a Antiguidade e a maneira com que foi legada à posteridade, em função de sua participação direta no regime de Vichy como ministro da educação. "Durante o Regime Vichy, no período compreendido entre 23 de fevereiro de 1941 e 16 de abril de 1942, Jérôme Carcopino, já à época consagrado historiador, arqueólogo e epigrafista do mundo romano, exerce a função de secretário de Estado, com estatuto de ministro na área de Educação" (p. 127). Para evidenciar essa questão, o autor reconstitui a participação de Jérôme Carcopino no interior do regime e a forma como os estudos clássicos eram produzidos durante esse período.

Ministro de Vichy, Carcopino é o intelectual chamado à ação. Suas posturas face ao Regime se inscrevem na sua trajetória acadêmica, nas interfaces de múltiplas e contraditórias ideologias, diante das quais sempre teve claras as suas opções. Desejoso de ser visto como intelectual e não como político (...), é o intelectual a serviço da política. Sua atuação política não se dissocia de sua obra acadêmica; esta possibilita a compreensão daquela e se apresenta, a um só tempo, 
como continuidade e ruptura da mesma. O estudo do Regime de Vichy e do papel de Carcopino no mesmo período conduz, inelutavelmente, à atestação do envolvimento do historiador com o colaboracionismo de Estado, com tudo que implica esse colaboracionismo. Mas conduz, também, à necessidade de reflexão acerca da História e do papel do historiador, bem como à irrefutável relação que este mantém com os poderes. (p. 151)

Por esse motivo, mesmo os estudos recentes sobre esse importante romanista, na França, levam em consideração, antes de ser analisada sua produção, a sua participação no Regime.

No quarto capítulo, História da Antiguidade e as extremas direitas francesas, a pesada herança de Vichy, revela-se que não apenas as obras de Carcopino foram lidas e interpretadas pela posteridade, de acordo com a sua participação no Regime de Vichy, mas o próprio regime deixou suas marcas na produção histórica francesa, em especial nas extremas direitas. $\mathrm{O}$ autor demonstra como os grupos que surgiram no imediato pós-guerra na França, a Nouvelle Droite, a Europe Acton, o GRECE e o Club de l'Horloge, acabaram sendo as matrizes ideológicas dos grupos de direita que foram se formando a partir da década de 1970. Nesse sentido, ressalta-se a participação do Front National na luta contra a imigração, os imigrantes e a Gália, e o papel exercido pela Antiguidade em Terre et Peuple para demarcar e justificar a 'guerra étnica', pois a "Antiguidade é, aqui, mais uma vez, um dos principais veículos da ideologia direitista" (p. 21). E:

É na França de Vichy, com suas leis racistas que retiram direitos tendo como pretexto a origem dos cidadãos (...) que se inspira o F. N. [o Front National]. (...) A identidade nacional ancorada no mito gaulês permite, assim, o reencontro com o passado ideal, distante e que tem na tradição gaulesa, em sua longevidade, a resposta para os dramas atuais da sociedade francesa. (p. 178-9) 
Assim, nessa mesma linha, ainda que com suas peculiaridades, defensor "de uma espécie de enraizamento cultural e de uma fidelidade identitária, o circulo T. P. [de Terre et Peuple] tem a História, desde os gregos e romanos, como testemunha dos fracassos e das derrocadas das sociedades multiculturais" (p. 190). E sobre esse aspecto, o grupo procuraria justificar sua 'guerra total', com ênfase nas questões étnicas.

Por suas qualidades, essa obra traz uma bela contribuição para um melhor entendimento de como a História, e certos grupos e sociedades do passado, são utilizados, em diferentes momentos, para justificar as ações no presente. Demonstrando como se utilizou, e também se abusou, do passado gaulês, romano e galo-romano na França durante o Regime de Vichy, e a herança que essas estratégias políticas e intelectuais deixaram para os partidos e grupos de extrema direita no país nos anos 80 e 90, o autor apresenta pormenorizadamente as relações entre História Antiga e História Contemporânea, e destaca que nem sempre as relações entre passado e presente são somente (ou completamente) 'lineares', mas sim dependem diretamente das especificidades e circunstâncias de cada momento histórico.

\section{Referências Bibliográficas:}

BANN, S. As invenções da História: ensaios sobre a representação do passado. Tradução de Flávia Vilas Boas. São Paulo: Edunesp, 1994.

CHESNEAUX, J. Devemos fazer tabula rasa do passado? Sobre a história e os historiadores. Tradução de Marcos A. da Silva. São Paulo: Ática, 1995.

DUBY, G. O domingo de Bouvines, 27 de julho de 1214. Tradução de Maria Cristina Frias. Rio de Janeiro: Paz e Terra, 1993.

GIRARDET, R. Mitos e mitologias políticas. São Paulo: Companhia das Letras, 1987. GOMES, A. C. História e historiadores. A política cultural do estado novo. Rio de Janeiro: FGV, 1996.

HARTOG, F. Régimes d'historicité. Présentisme et expériences du temps. Paris: Le Seuil, 2003. 


\section{Diogo da Silva Roiz}

. O espelho de Heródoto: ensaios sobre a representação do outro. Tradução

de Jacyntho Lins Brandão. Belo Horizonte: Ed. UFMG, 1999.

HOBSBAWM, E. \& RANGER, T. (org.) A invenção das tradições. Tradução de Celina Cardim Cavalcante - $2^{\mathrm{a}}$ edição - Rio de Janeiro: Paz e Terra, 1997.

MARX, K. O Dezoito Brumário e cartas a Kugelmann. Rio de Janeiro: Paz e Terra, 1969. 